\title{
Modalities of Using Learning Objects for Intelligent Agents in Learning
}

\author{
Dorian Stoilescu \\ Ontario Institute for Studies in Education, University of Toronto, \\ Toronto, Canada
}

\author{
dstoilescu@oise.utoronto.ca
}

\begin{abstract}
This article details some common characteristics of applications using Intelligent Agents as they relate to Learning Objects as software systems in delivering education. Readapting Learning Objects to different categories of learners constitutes a challenge for Intelligent Agents in their effort to provide a large scale of collaboration between different e-learning organizations. In order not only to have efficient access to Learning Objects, but also to offer to learners tutoring and mentoring help, collaborative and cooperative learning strategies, learning advancements, and social interactions, Intelligent Agents have been highly recommended by a number of researchers. This study investigates how these e-learning applications are designed, how students' differences are explored, and how these software systems are able to improve learning and teaching performances.
\end{abstract}

Keywords: Learning Objects, Intelligent Agents, Adaptive Systems, Intelligent Tutoring Systems, Learning Management Systems, Learning Services.

\section{Introduction}

Digital resources are already widely used in today's education, from early education to adult learning, from individual learners to large classrooms. The pace of growth is considerably fast. Especially for e-learning, there have been consistent leaps forward in the methods available to group, share, retrieve, and re-use curricular information through software applications. The Internet and multimedia resources have already become of great importance in learning (Lee, Junginger, \& Geller, 2003). Separate technologies and organizations are merging in order to deliver multi-faceted and multimedia channels for content that makes e-learning more effective.

Many technology experts and teachers are working together to launch a set of methods and standards that enable easy re-use, recombination, and transfer of content between individuals, institutions, and countries. More specifically, the goals are:

Material published as part of this publication, either on-line or in print, is copyrighted by the Informing Science Institute. Permission to make digital or paper copy of part or all of these works for personal or classroom use is granted without fee provided that the copies are not made or distributed for profit or commercial advantage AND that copies 1) bear this notice in full and 2) give the full citation on the first page. It is permissible to abstract these works so long as credit is given. To copy in all other cases or to republish or to post on a server or to redistribute to lists requires specific permission and payment of a fee. Contact 0HPublisher@InformingScience.org to request redistribution permission. a. Anywhere, Anytime: Delivering the learning content anywhere is a goal that underpins the e-learning paradigm. Also, in the case of asynchronous communication, the paradigm could be completed with the mention of the anytime characteristic.

b. Flexibility: Course materials can be automatically adjusted in order to be accessed by a large variety of devices, 
ranging from the workstations and desktop PCs to Personal Digital Assistants (PDAs) and mobile phones.

c. Personalization: The courseware's content delivers a unique learning experience appropriate to the capabilities, skills, and needs of each individual.

d. Adaptivity: The system is not only able to profile users but is also aware of changes.

e. Contextualization: The content is delivered considering a specific sociocultural environment.

This study describes specific efforts to increase and diversify learners' access to e-learning opportunities. More precisely, it investigates specific ways in which digital resources are designed and stored into different systems and organizations, and automatically delivered to learners. How can the information be digitized in order to be accessible, inter-operational, purposeful, and useful in storing different areas of knowledge? How can the digital resources be efficiently used to teach students? What kind of application should be designed in order to explore digital resources better?

Since 1994 numerous organizations have been attempting to organize the curricular contents around the concept of Learning Objects. After many Learning Objects were collected, stored, and evaluated, the problem of efficiently using them for educational purposes is still a challenge. This investigation focuses on a specific direction - the use of Intelligent Agents in processing Learning Objects. This paper is organized in five sections. After this introductory section, the second section summarizes the basic properties of Intelligent Agents and Learning Objects. In the next section, some of the educational perspectives brought by intelligent-agent applications are presented. In the fourth chapter software characteristics of educational applications using Intelligent Agents in manipulating Learning Objects, areas of research, and challenges of building these types of applications are discussed. The final section contains an overall perspective, discussing some drawbacks and main trends for Intelligent Agent applications using Learning Objects.

\section{Main Theories about Learning Objects and Intelligent Agents}

This section presents the main concepts and the evolution of Learning Objects and Intelligent Agents concepts, considered separately. First, we will describe the concept of Learning Object. There is no universal definition of Learning Objects. The Learning Object concept was first popularized by Wayne Hodgins in 1994, during his activity at the Computer Education Management Association (CeMA) working group, when he introduced the term "Learning Object" (Polsani, 2003). The origin of this term started to be significantly related with the Object Oriented Programming (OOP) paradigm (Bratina, Hayes, \& Blumsack, 2002; Robson, 1999).

In time, the meaning of Learning Object changed. Learning Objects became more concerned with the relevance of information, knowledge, and learning content than with the OOP aspects. A first attempt to standardize the notion of Learning Object was done by IEEE (the Institute of Electrical and Electronics Engineers, 2002). According to the definition of the IEEE committee, a Learning Object could be any piece of information; it was not significant whether the information is digital or not. Therefore, this definition was considered too general. For Quinn and Hobbs (2000) a Learning Object is anything digital. In this case, all the content from Web pages and external devices would consist entirely of Learning Objects. It does not mention if the information has an educational or pedagogical purpose or not. This definition was also found to be too broad.

Better definitions result by considering the two related fundamental aspects of Learning Objects: the digital aspect and the educational purpose (McGreal, 2004; Polsani, 2003). Sometimes, the 
definitions of a Learning Object are associated only with specific pedagogical ways of delivering the content. For instance, for Corporate Communications Interactive (CCI) (2001), a Learning Object is basically a pedagogical item consisting of text, image, sound, and multimedia. In order to be considered a "Learning Object", the item should be "tight", self-contained, and have multimedia teaching modules. For them, a typical module should comprise the following: an overview, a challenge, a lesson, a test, and a summary.

Today there are many standards for Learning Objects, which give them a large audience to users. From the most widespread standards we could mention:

a. IEEE Learning Object Metadata (LOM) (IEEE, 2002). This was the first important standard created for the purpose of defining metadata for Learning Objects. Almost all implementations refer to this standard although the model is considered now too simplistic and outdated.

b. The Dublin Core Initiative (DC) (2006) is a 15-element set intended to define and facilitate the discovery of electronic resources. This format was widely accepted by a large number of librarians and digital libraries.

c. Educational Modeling Language (EML) was developed by the Open University of the Netherlands. It is characterized as "XML style" for defining different fields designed for providing presentations in education and training processes (Koper \& Manderveld, 2004).

d. Synchronized Multimedia Integration Language (SMIL) was developed by the World Wide Web Consortium (W3C), (2005). SMIL was designed to facilitate a wider authoring for multimedia presentations over the Web. This standardization was adopted by the World Wide Web Consortium and is an easy-to-learn XML-style, allowing easy design of multimedia presentations.

e. Sharable Content Object Reference Model (SCORM) was introduced by the Advanced Distributed Learning Initiative (ADL, 2004) and supported by powerful organizations. Although there are many fields required to be completed and it is considered by many to be difficult, this implementation is considered very consistent by experts. This standard is today the most widely accepted specification in North America.

The second part of this section discusses about Intelligent Agents and their use in education. First, a general definition of Intelligent Agents is provided. According to Wooldridge and Jennings (1995), an Intelligent Agent is a program that has the followings:

a. Autonomy: Agents work on their own and have a high degree of control over their actions and internal state.

b. Social ability: Agents react with human and other agents via an agent-communication language.

c. Reactivity: Agents perceive their requests and respond in the same time to changes that occur in their environment.

d. Pro-Activeness: Agents not only perform specific tasks but they take the initiative.

Intelligent Agents can be used in many domains, such as electronic commerce, manufacturing, military, education, business, psychology, and sociology. Usually, an agent is given a very small and well-defined orientation and processing tasks in the background. In this paper the focus is more on educational agents. The focus is to provide perspectives about how agents should be designed in order to explore a learning repository with Learning Objects and to offer tutoring, mentoring, teaching, and social interactions. According to Sampson, Karagiannidis, and Kinshuk (2002), an agent has the following purposes: 

a. Information seekers;
b. Personal assistants;
c. Information managers;
d. Planning agents;
e. Coordination agents;
f. Collaborative schedulers;
g. User representatives.

There are many roles in which IAs can be utilized. A special subsection will describe later details about educational technological domains that incorporate intelligent-agent technologies.

\section{Educational Perspectives}

This section will deal with educational perspective brought by applications using Learning Objects for Intelligent Agents. The focus of discussion will be more on educational perspectives brought by intelligent-agent applications. We are interested to see what roles were implemented, what educational theories were considered, and how these were modeled.

\section{Educational Aspects Modeled by Intelligent Agents}

Learning theories and cognitive styles were discovered earlier than Learning Management Systems. From all educational models, it was important to select those which offered the possibility of being easily implemented by using software simulations. Hawryszkiewycz (2007) offered some insights about modeling and implementing flexible learning processes. In fact, there are many educational models offering a diverse software modeling perspectives for agents, which became a dominant tendency of the new generation of learning systems.

The education community advocates two distinct learning strategies: the objectivist model and the constructivist model (Jonassen, Davidson, Collins, Campbell, \& Haag, 1995). The former model considers the world structured and objective. Consequently, the role of the learner is to reflect reality as presented by instructor or textbooks. In an objectivist technology model, learners are guided in a step-by-step process without considering differences for learners' backgrounds, their potentials, and their learning strategies. In contrast, the constructivist model acknowledges that a learner's reality is constructed by his or her mind. The mind is filtering the information from the world according with its subjective perspectives. A constructivist software in learning allows students to build their learning process in a personalized path, according with their personality, abilities, and goals.

People do not learn in the same way. Learners and educational technologists were not satisfied with the objective model that is based more on simulating rigid instructor tasks while the individual differences of learners are not approached. For instance, Atif, Benlamri, and Berri (2003) opted for implementing a constructivist model for learning. Winn (2002) gave a special consideration to constructivism, mentioning that this approach has a major impact in changing educational systems. In fact, in the last time constructivist frameworks have been the major trends for researchers in their effort to build performing e-learning educational systems.

Not all educational theories can be implemented in a digital format. However, there are several educational perspectives that are already implemented:

a. Multiple Intelligence (Gardner, 1993) divides learning styles as dealing with words (Verbal/Linguistic), questions (Logical/Mathematical), pictures (Visual/Spatial), music 
(Music/Rhythmic), moving (Body/Kinesthetic), socializing (Interpersonal), and personal insights (Intrapersonal).

b. The Learning Style Inventory (Kolb, 1984) describes learning styles on a continuum running from concrete experience, through reflective observation, to abstract conceptualization, and finally active experimentation.

c. Honey and Mumford Learning Styles (Honey, 2001) describe the following main learning styles: theorist, activist, reflector, and pragmatist.

d. The Mind Style and Delineator Style of Gregorc (Gregorc, 2006) uses the following main components: abstract-sequential, abstract-random, concrete-sequential, concreterandom.

e. The Learning Style Model of Felder-Silverman (Felder \& Spurlin, 2005) situates the student's learning style within a four-dimensional space, with the following four independent descriptors: sensing learners vs. intuitive learners; visual learners vs. verbal learners; active learners vs. reflective learners; sequential learners vs. global learners (Sun, Joy, \& Griffiths, 2005b).

f. The Learning Orientation Theory uses three main types of learners: transforming, performing, and conforming. In order to be effective for learning, it was argued that there are three main requirements for agents as mentors: 1) regulated intelligence; 2) the existence of a persona; and 3) pedagogical control.

Dara-Abrams (2002) designed a hypermedia learning system able to explore the cognitive Theory of Multiple Intelligences in order to verify that this theory is suited to an online learning environment. The research was conducted in three stages: user characterization and understanding goals, development of prototype adaptive hypermedia framework and learning modules, and formative evaluation of prototype. The entire study was conducted online via a Web-based framework developed for the purposes of the study. The evaluation from the current research indicated that further applications of the Theory of Multiple Intelligences, the Entry Point Framework, multiple representations, and the Teaching for Understanding Framework will improve the prototype, offering rich multi-intelligent adaptive hypermedia content presentations and moving toward an implementation of "anytime, anywhere, anyone, anyhow" online learning.

Using metadata annotation, Mustaro and Silveiro (2006) proposed an implementation able to identify prime learning styles that learning objects offer, according with theoretical learning styles developed by Felder, Kolb, or Gardner. Also, Mustaro and Silveiro implemented an instructional design framework based on the theory of cognitive learning processes developed by Gagné (Gagné, Brigss, \& Wager, 1992). This implementation contained nine distinct stages:
a. Attention;
b. Expectation;
c. Recuperation;
d. Selective perception;
e. Semantic codification;
f. Response;
g. Reinforcement;
h. Performance;
i. Generalization. 


\section{Roles of Intelligent Agents Used in Education}

Intelligent Agents technology has been applied in a variety of educational settings:

a. Information retrieval (Hiltz \& Wellman, 1997). This is often considered "the simplest" activity. In this case, agents perform searches for information, based on various criteria.

b. Processing and distributing information about students.

c. Feedback collection (Huhns \& Mohamed, 1999). In this case, the system collects information about each student who participates in learning, according to their background.

d. Teaching agents (Selker, 1994). This type of agent will perform directly the act of teaching. It contains scenarios to present and deliver new content and lessons to students, keeping into account details about personal profile.

e. Agents for checking assignments. This category of agents can establish assignments with different levels of difficulty and automatically evaluate the results.

f. Agents for peer-help environments (Vassileva et al., 1999). This type of agent facilitates the interaction and the dialog with peers. It contains different scenarios to facilitate interactions.

g. Agents for providing group-support online (Whatley, Staniford, Beer, \& Scown, 1999). In this case, the scenario provides both student-teacher and student-student support interactions.

h. Tutoring agents (Solomos \& Avouris, 1999). This type of agent will emulate a peer-topeer tutoring style.

i. Agents for performing interactions and collaborations in a network community (Lin \& Holt, 2001). In this case, the settings have a more constructivist orientation. This type of Intelligent Agents is focused to produce more practical questions for the particular type of community, keeping into account different social aspects about community. In particular, cultural and social aspects are especially considered in this set of interactions.

Because the definition of the transfer of knowledge varies widely, it can be inferred that this model of applications that use Intelligent Agents in an educational environment is only a very general approach. More details are required in order to precisely control the creation of the contents of each educational item, to update, to modify the lessons' contents, to evaluate, and to efficiently use data. In our case, Intelligent Agents should only partially replace the role of teachers and students. The fundamental problem with which this study is concerned is to see how the combination of these two important paradigms is implemented in one application.

A general strategy in using Intelligent Agents in education was designed by Jaques, Andrade, Jung, Bordini, and Vicari (2003). According to them, an application using Intelligent Agents in an educational environment should have the following categories of agents:
a. Diagnostic Agent;
b. Mediating Agent;
c. Collaboration Agent;
d. Social Agent;
e. Semiotic Agent.

Researchers appreciated that Intelligent Agents could be successfully used in empowering learners to use e-learning settings. For instance, Sampson et al. (2002) inferred that intelligent-agent 
technology seems to be a promising perspective in approaching educational environments, especially influenced by Internet technologies.

\section{The Challenge of Building Applications Able to Efficiently Use Learning Objects}

This section details how Learning Objects facilitate Intelligent Agents in order to offer them opportunities to explore educational contexts. The architectural properties of Learning Objects are well described by Atif et al. (2003). They mentioned the fact that Learning Objects are servers as well as clients. According to Sampson et al. (2002) Intelligent Agents have four major characteristics defining their behavior:
a. Autonomy;
b. Responsiveness or reactiveness;
c. Pro-activeness;
d. Social ability.

For the entire class of applications, the main challenge for researchers was to implement these requirements through the educational contexts and rules that Learning Objects offered and, in the same time, restricted the intelligent processing.

\section{Relevant Advantages of Applications Using Learning Objects}

Many researchers (e.g. Berlanga \& Garcia, 2004; Or-Bach, 2004; Varlamis \& Apostolakis, 2006) have identified the most important characteristics that applications using LO should possess:

a. Interoperability. For the case of learning objects, interoperability requires the instructional components developed with a set of tools and platforms to be usable in other systems and software tools. Today interoperability is required by all systems.

b. Reusability. In the case of systems using Learning Objects, reusability requires that learning systems be able to (re)integrate the instructional components into a variety of contexts, applications and systems.

c. Accessibility. In order for Learning Objects to be accessible, it is required that the localization and access of instructional materials be permitted, no matter their spatial situation. In the beginning, many people considered Learning Objects as being neutral. However, research (Friesen, 2004) has shown that Learning Objects are not neutral. They are realized by different organizations and countries for different purposes. Consequentially, often it is often necessary to verify the accessibility, the source of provenance, and the biases.

d. Durability. Supporting new technological educational systems requires maintaining compatibility with previous versions. Learning Objects have to adapt to changes in technology without it being necessary to redesign them.

e. Standardization. Standardization, especially in the Learning Objects area, requires clear specification for interoperability and processes. Standardization is extended to all aspects of the LO functionalities. However, often incomplete or unclear standards have been encountered. With all of these, in Learning Objects technology, standardization has many advantages (Varlamis \& Apostolakis, 2006).

f. Manageability. For systems using Learning Objects, manageability requires tracking and setting information about the learner and the educational content. 


\section{Practical Problems in Using Learning Objects}

The first versions of software applications used Learning Objects as opaque entities, impossible to adapt to different versions of teaching styles or to learners' needs (Manouselis \& Sampson, 2002). However, in the last generation of educational software projects, the tendency to particularize the product according to learning and teaching styles became general.

For instance, Atif et al. (2003) tried to provide an algorithm to construct individual learning routes that are adjusted to the learner's profile as well as open implementation able to accept integration of a large scale of learning resources. Categorization is a very important aspect in a learning system (Or-Bach, 2004). If it is only about a few courses, categorization is not difficult. However, in systems with large amount of data, there are serious problems in maintaining consistency in categorization.

Some researchers (Baylor 2000; Jaques et al., 2003) discussed social requirements that Intelligent Agents must have in order to develop educational purposes. For instance, Baylor (2000) considered incorporating usability and human-computer interaction properties, such as the anthropomorphic qualities and social relationship between learner and agent. Sun, Joy, and Griffiths (2005a) mentioned that Intelligent Agents could process Learning Objects to facilitate personalization and adaptability.

In order to offer a better feedback from students, a great number of researchers considered it essential to model, simulate, and implement the current educational theories into Intelligent Agents application. Constructivism, cognitive theories, and learning styles were intensely explored in order to improve the results of educational agents. The following section will discuss in detail educational theories implemented for educational agents.

\section{Areas of Software Applications Using Intelligent Agents in Manipulating Learning Objects}

In relation to the way people use the metadata, learning object technologies can have: a) Tightly Coupled Metadata and b) Loosely Coupled Metadata. Tightly coupled metadata are more associated with software engineering, while loosely coupled metadata are associated more with the semantic Web. This is only a general approach. In fact, the use of Intelligent Agents in manipulating Learning Objects is applied in many areas of research. Sometimes, these domains do not have precise criteria to be divided. The areas of research for Intelligent Agents using Learning Objects are:

a. Instructional Systems Development (ISD) and Instructional Management Systems (IMS) (van Rosmalen et al., 2005);

b. Learning Content Management and Learning Management Systems (LMS) (Sampson et al., 2002);

c. Computer Supported Collaborative Learning (CSCL) systems (Jaques et al., 2002);

d. Community-Based Learning (CBL) (Lin \& Holt, 2001; Santos, Boticario, \& Barrera, 2004);

e. Cooperative Learning emulations (Lee \& Geller, 2002);

f. Adaptive Strategies: Adaptive Text Presentation (ATP), Adaptive Multimedia Presentation (AMP), Adaptive Hypermedia Systems (AHS) and Web Based Adapted Educational Systems (WBAES), Adaptive and Collaborative Learning (ACL) and Adaptive Learning Systems (ALS) (Brusilovsky, 1994). 
g. Semantic Web (SW) (Carbonaro, Ferrini, \& Zamboni, 2005; Ishaya, 2005; Stojanovic, Staab \& Studer, 2001).

h. Intelligent Tutoring Systems (ITS) (Solomos \& Avouris 1999);

The main question that researchers had was what are the paramount features that make a learning system intelligent? Of special interest is the area of Intelligent Tutoring Systems (ITS). ITS theory uses knowledge about domain, student, teaching strategies, evaluations, and tutoring.

One of the most important found features was adaptability. From the new domains, one of them is Adaptive Hypermedia Systems (AHS). Adaptive Hypermedia Systems apply different forms of learners' models to adapt the content and the links of the hypermedia environment. Brusilovsky (2001) offered a detailed solution about how and what can be adapted. Mainly, there are two types of taxonomy: adaptive presentation and adaptive navigation. Adaptive presentation means the adaptation of multimedia items to the specificities that the learner has. Adaptive navigation includes link hiding, link sorting, and the dynamic configuration of the map's website. For each user, AHS builds a model according with the user's goals, preferences, and knowledge. More specifically, the links from each hypermedia context are configured so that the user can use them in a personalized way, according to his or her individual profile. Users with different skills' levels of the subjects appreciate the adaptive navigation.

Intelligent-agent strategies and Learning Objects were successfully joined together in Learning Management Systems (LMS). For the purpose of providing more flexibility in LMS, Santos et al. (2004) introduced the concept of intelligent LMS (iLMS) through using an intelligent-agent strategy. Van Rosmalen et al. (2005) discussed the main tendencies of Instructional Management Systems (IMS). In relation with learning design (LD) aspect, they mentioned that IMS LD should support open frameworks for the purpose of modeling competency, collaborative learning interactions, and personalization. Intelligent Agents in teaching are used also in Computer Supported Collaborative Learning Systems (CSCL) (Jaques et al., 2002).

One of the most general domains where Intelligent Agent applications were used is Instructional Systems Development (ISD). According to van Rosmalen et al. (2005), ISD have a wide scope. For them the educational process is divided into five steps:
a. Analysis;
b. Design;
c. Production;
d. Implementation and delivery;
e. Summative evaluation.

Marin and Hunger (2005) developed the notion of collaboration in PASSENGER, built at the University of Duisburg-Essen, Germany, for students considered low achievers. Collaborative learning is very important for it provides emotional support for students who have difficulties in their courses and helps them to deal with course's requirements and support each other. In this case, the system is an intelligent-agent application designed to support collaborative learning between two or more geographically dispersed students through e-learning.

Other important applications apply to the Semantic Web. The resources are processed to extract senses (not just words) from the documents. According to Stojanovic et al. (2001) there are important benefits of semantics facilities:

"The new generation of the web, the so-called Semantic Web, appears as a promising technology for implementing eLearning. The Semantic Web constitutes an environment in which human and machine agents will communicate on a semantic basis" (p. 1). 
In this case, the classification, recommendation, and sharing phases take advantage of the word senses to classify, retrieve, and suggest documents with high semantic relevance with respect to the student and resource models.

\section{Multi-Agent Applications that Have Teaching Performing Tasks}

Samples of software application using multi-agents in manipulating Learning Objects are:

a. KnowledgeTree (Brusilovsky, 2003);

b. SAIL (Slotta \& Aleahmad, 2007);

c. aLFanet (van Rosmalen et al., 2005);

d. MASPLANG (Pena, Marzo, \& Rosa, 2005);

e. Knowledge on Demand European Project (KOD) (Karagiannidis \& Sampson, 2004);

f. Agent-Based Web Learning System (ABWLS) (Huang, Cheng, \& Fu, 2004);

g. CADMOS (Retalis \& Papasalouros, 2004);

h. Collaborative and Sharable Learning system (CoSL) (Lee \& Geller, 2002);

i. Active Learning For Adaptive internet (ALFanet) (Santos et al., 2004).

KnowledgeTree (Brusilovsky, 2003) has a distributed architecture for adaptive e-learning conceived for the reusing of educational activities. It tries to replace the monolithic structure of LMS with a community of distributed services (or Servers). The system architecture has four different types of services:
a. Activity services;
b. Value-adding services;
c. Learning portals services;
d. Student model services.

An interesting design is offered in the project SAIL (Scalable Architecture for Interactive Learning, 2006) designed by Slotta \& Aleahmad (2007). SAIL uses Java-based technology and allows flexible ways to deploy curricula by using a special strategy to manipulate Learning Objects. SAIL developed its own types of items called curnits, pods, rims, and socks. A SAIL-based curriculum unit is called a curnit (word invented from "curriculum" and "unit" abridged). A curnit is an authored artifact. It has no information on its use. A curnit consists of a tree of pods. There is one root pod for the curnit and it can have any number of children, as can each child descendant.

Technologically, each pod can contains multiple JavaBeans and is the basic unit of authoring reuse. They organize bean instances, class dependencies, binary resources, and rims (see below) and they make these reusable in other curnits. Pods will be designed to support subscribed copy and prototyping; they can reference values exported from other pods which are set at pod reassembly time. In this case each separate pod can be reconstituted into the full hierarchy in the curnit. Pods are also the context of rims; these rims provide data generated during the session. Data passes through a rim into a sock. Rim is the authored artifact but sock is where data is actually stored over the course of the offering. It is a virtual container for the use of a rim by a set of users.

To make use of a curnit, an offering is created for this. More specifically, an offering defines a temporary context of the use of curnit. It specifies attributes such as ownership, access restric- 
tions, roles' permissions, and contexts of interaction. The offering also handles updates and modifications over the course.

\section{Concluding Comments}

From the previous sections, we noticed that, based on adaptations of the e-learning model, using Intelligent Agent in processing Learning Objects should provide learning at reduced costs, increasing access to curricular knowledge, and a better accountability for learners. In this final section we will discuss some drawbacks and possible solutions and trends of these class of applications.

\section{Some Critics of Intelligent Agents Implementations Using Learning Objects}

There were several discomforts and inadequacies in approaching this class of implementations. Therefore, several opinions will be considered in this section. First, there are opponents of the tendency toward standardization in education. For them, Learning Object technology is from the start considered to be a wrong choice (Friesen, 2004).

Secondly, in this paper, adaptability was considered the most important criteria in discussing Intelligent Agents in learning. This concept is still considered a new domain (van Rosmalen et al., 2005) and stirred many controversies. Adaptation procedures are still pretty clumsy; the creation, reusability and extension of learning objects are underperforming. At first sight, the adaptability pursued by Intelligent Agents seems very natural. However, as we saw in this study, it is very difficult to obtain at this moment.

Third, granularity of concepts is a serious issue when Learning Objects are discussed (Qin \& Finnerman, 2002). What is the degree of granularity so that the object can be reused in a variety of situations and in a meaningful context? For Or-Bach (2004) the concept of granularity is a serious issue when Intelligent Agents tried to design learning activities involving high order skills. Fourth, nowadays even the use of electronic format is still challenging for many students (Buzzetto-More, Sweat-Guy, \& Elobaid, 2007).

Fifth, today all Intelligent Agents perform far below normal teaching standards and performing applications in teaching are still missing. One of the most preeminent researchers, Brusilovsky (2003) mentioned that there are a great number of software applications for learning but too little research was dedicated to discussing their efficiency. Sixth, even if the concept of Intelligent Agent could offer a successfully potential implementation, there are researchers who are skeptical about the efficiency of Intelligent Agents in manipulating Learning Objects (Qin \& Godby, 2003; Wiley, 2003). For instance, Qin and Goodby (2003) mentioned that the standards for the definition of metadata do not offer enough opportunities to fully explore the content of the associated Learning Objects. Consequentially, it can be inferred that any Intelligent Agent does not have the opportunity to explore the full value of the learning content from a Learning Object. Also, Friesen (2004) is concerned about the lack of educational meaning when the interactions or technical combinations with Learning Objects do not produce educational relevance.

Right now, there is not any popular application of Intelligent Agents using Learning Objects that has entered into the educational global mainstream. There are only projects and tests. Sometimes local solutions could not be generalized. For instance, Or-Bach (2004) recommended that the creation of metadata objects should be done by students. Of course, this tendency is welcomed as providing more hands-on experience to learners but, obviously, without an adequate supervision, inter-operability and the coherence could be easily lost in this case. 
Applications should ensure Web-readability and the capacity to export/import Learning Objects to different systems. In order to be able to offer improving performances for these IA applications, our educational systems should use more rigorous instructional design strategies, learning styles and cognitive learners theories. The dialogue between educators and technicians should be improved in order to obtain in-time feedback about Learning Objects and Intelligent Agents performances. A better software simulation should be designed for social interactions. Also, the applications should perform better in techniques of delivering learning towards profiling extraction by introducing a better conjunction of static and dynamic profiling mechanisms.

\section{Further Trends}

As mentioned before, Intelligent Agents using Learning Objects have proved already certain advantages. Many companies and universities built new specifications that connect more specifically the two fundamental notions: Learning Objects and Intelligent Agents. For instance, some of the introduced notions are:

a. Publisher/Subscriber Communication for Adaptive Learning (Lee et al., 2003).

b. Agent-based Online Learning (Lin \& Holt, 2001).

c. Pedagogical Agents (Jaques et al., 2002).

d. Agent Based Learning Objects (ABLO) (Mohammed \& Mohan, 2005).

e. Intelligent Learning Objects (ILO) (Silveira, Gomes, Pinto, \& Vicari, 2004).

e. Smart Learning Objects (SLO) (Mohan \& Brooks, 2003).

f. Adaptive Learning Objects (Brusilovsky, 2003; Mustaro \& Silveira, 2006).

Another important event is the revolution produced in the software industry by services. In recent years, the notion of service became fundamental. As the service oriented paradigm became more mature, the Learning Objects paradigm started to move towards the Learning Services paradigm (Ishaya, 2005).

Future studies are required in order to evaluate the efficiency of these newly designed projects in learning services. Also, in order to connect and pool together curricular information from distant computers, new trends mentioned the great potential of the strategy of building grid learning services. According to Nkambou, Gouardères, and Woolf (2005) grid learning services provides a large range of services and resources that fully value the effects of connectivity. These would significantly improve the support for personalized access, negotiation and dialog with pervasive learning communities.

\section{Acknowledgments}

I would like to thank Dr. Ziad Kobti and Dr. Richard Frost who encouraged and helped me in this research and also to all those who gave me feedback from my presentations of this project at conferences, especially the Association for the Advancement of Computing in Education (AACEElearn, Quebec 2007) and International Association for Development of the Information SocietyIntelligent Systems and Agents (IADIS-ISA, Lisbon 2007).

\section{References}

ADL (2004). Advanced Distributed Learning. Retrieved January 10, 2007 from www.adlnet.org

Atif, Y., Benlamri, R., \& Berri, J. (2003). Learning objects based framework for self-adapting learning. Education and Information Technologies, 8(4), 345-368. 
Baylor, A. (2000). Beyond butlers: Intelligent agents as mentors. Journal of Educational Computing Research, 22(4), 373-382.

Berlanga, A., \& García F. J. (2004). Towards adaptive learning designs. In P. De Bra \& W. Nejdl (Eds.), Adaptive hypermedia and adaptive web-based systems (pp. 372-375). Springer-Verlag: Berlin.

Bratina, T., Hayes, D., \& Blumsack, S. (2002). Preparing teachers to use learning objects. The Technology Source, November/December. Retrieved May 10, 2006 from http://technologysource.org/?view=article \&id $=242$

Brusilovsky, P. (1994). Student model centered architecture for intelligent learning environment. Proceedings of the Fourth International Conference on User Modeling. MITRE, Hyannis, MA, (pp. 31- 36). Retrieved May 10, 2006, from http://www2.sis.pitt.edu/ peterb/papers/UM94.html

Brusilovsky, P. (2001). Adaptive hypermedia. User Modelling and User-Adapted Interaction, 11, 87-110.

Brusilovsky, P. (2003) A component-based distributed architecture for adaptive Web-based education. In U. Hoppe, F. Verdejo, \& J. Kay (Eds.), Artificial intelligence in education: Shaping the future of learning through intelligent technologies. Proceedings of AI-ED'2004, Sydney, Australia, July 20-24, (pp. 386-388), Amsterdam: OIS Press.

Buzzetto-More, N., Sweat-Guy, R., \& Elobaid, M. (2007). Reading in a digital age: E-books are students ready for this learning object? Interdisciplinary Journal of Knowledge and Learning Objects, 3, 239250. Retrieved December 21, 2007 from http://ijklo.org/Volume3/IJKLOv3p239-250Buzzetto.pdf

Carbonaro, A., Ferrini, R., \& Zamboni, M. A. (2005). Considering semantic abilities to improve a webbased distance learning system. Proceedings of the International Workshop Held in conjunction with the 16th ACM Conference on Hypertext and Hypermedia (HT'05) Salzburg, Austria, (pp. 27-32).

Corporate Communications Interactive [CCI]. (2001). Corporate Communications Interactive eSchool Learning Object Framework. (White Paper). Retrieved April 10, 2006 from http://www.softchoice.com/services/training/pdf/lofwhitepaper.pdf

Dara-Abrams, B. P. (2002). Applying multi-intelligent, adaptive hypermedia to online learning. Unpublished doctoral dissertation, Union Institute and University Graduate College, UK.

The Dublin Core Initiative [DC]. (2006). The Dublin Core Initiative Standardization. Retrieved June 3, 2006 from http://www.dublincore.org

Felder, R. M., \& Spurlin, J. E. (2005). Applications, reliability, and validity of the index of learning styles. International Journal of Engineering Education, 21(1), 103-112.

Friesen, N. (2004). Three objections to learning objects and e-learning standards. In R. McGreal (Ed.), Online education using learning objects (pp. 59-70). London: Routledge.

Gagné, R. M., Brigss, L. J. \& Wager, W. (1992). Principles of instructional design. Orlando, FL: Harcourt Brace Jovanovich College Publishers.

Gardner, H. (1993). Intelligence reframed: Multiple intelligences for the 21st century. NY: Basic Books.

Gregorc, A. F. (2006). The mind style and delineator style of Gregorc instrument. Retrieved May 14, 2006 from: http://www.gregorc.com/instrume.html

Hawryszkiewycz, I. T. (2007). An engagement model for learning: Providing a framework to identify technology services. Interdisciplinary Journal of Knowledge and Learning Objects, 3, 219-228. Retrieved December 24, 2007 from http://www.ijklo.org/Volume3/IJKLOv3p219-228Hawr366.pdf

Hiltz, S. R., \& Wellman, B. (1997). Asynchronous learning networks as a virtual classroom. Communications of the ACM, 40(9), 44-49.

Honey, P. (2001). Honey and Mumford learning styles questionnaire. Retrieved April 22, 2006 from the PeterHoney Learning Web site: http://www.peterhoney.com/product/learningstyles 
Huang, Y. M., Cheng, J. N. W., \& Fu, K. T. C. H. (2004). Agent-based web learning system. IEEE Computer Society-Technical Committee on Learning Technology (TCLT), Learning Technologies Newsletter, April, 37-41.

Huhns, M., \& Mohamed, A. (1999). Benevolent agents. IEEE Internet Computing, 3(2), 96-98.

Institute of Electrical and Electronics Engineers, Inc. [IEEE]. (2002). Standard for Learning Object Metadata (LOM). Retrieved April 23, 2006 from IEEE Web site http://ltsc.ieee.org/wg12/files/LOM_1484_12_1_v1_Final_Draft.pdf

Ishaya, T. (2005). Ontologies for semantic integration of multimedia e-learning services. Computer systems and applications. Proceedings to the 3rd ACS/IEEE International Conference (pp. 883-888).

Jaques, P., Andrade, A., Jung, J., Bordini, R., \& Vicari, R. (2002). Using pedagogical agents to support collaborative distance learning. Proceedings of the CSCL 2002, University of Colorado, Boulder.

Jonassen, D., Davidson, M., Collins, M., Campbell, J. \& Haag, B. (1995). Constructivism and computer mediated communication in distance education. American Journal of Distance Education, 9, 7-25.

Karagiannidis, C., \& Sampson, D. (2004). Adaptation rules relating learning styles research and learning objects meta-data. Workshop on individual differences in adaptive hypermedia. Proceedings to the $3 \mathrm{rd}$ International Conference on Adaptive hypermedia and Adaptive Web-based Systems, August, Eindhoven.

Kolb, D. A. (1984). Experiential learning: Experience as the source of learning and development. Englewood Cliffs, NJ: Prentice-Hall.

Koper, R., \& Manderveld, J. (2004). Educational modeling language: Modeling reusable, interoperable, rich and personalized units of learning. British Journal of Educational Technology, 35(5), 537-551.

Lee, Y., \& Geller, J. (2002). A component-based architecture for adaptive, collaborative web-based learning. Proceedings from the First International Conference on Web (pp. 203-215).

Lee, Y., Junginger, M., \& Geller, J. (2003). High performance publisher/subscriber communication for adaptive, collaborative Web-based learning. Journal of Distributed Education Technology, 1(3), 14-27.

Lin, F., \& Holt, P. (2001). Towards agent-based online learning. Proceedings of the Fourth International Conference IASTED on Computer and Advanced Technology in Education (CATE). Banff, Canada, June, (pp. 124-129).

Manouselis, N., \& Sampson, D. (2002) Dynamic knowledge route selection for personalized learning environments using multiple criteria. Proceedings of the IASTED International Conference on Applied Informatics (pp. 351-356).

Marin, B. F., \& Hunger, A. (2005). Intelligent Agents: A new paradigm to support collaborative learning in distance education systems. Learning Technology Newsletter, 7(2), 18-20.

McGreal, R. (2004). Learning objects: A practical definition. International Journal of Instructional Technology and Distance Learning, 1(9), 21-32. Retrieved January 16, 2008 from http://www.itdl.org/Journal/Sep_04/article02.htm

Mohammed, P., \& Mohan, P. (2005). Agent based learning objects on the educational semantic web. Proceedings of the Second Conference in Intelligent Interactive Learning Object Repositories. Retrieved June 3, 2006 from http://www.lornet.org/presentation_i2lor_05/papers/i2lor05-14.pdf

Mohan, P., \& Brooks, C. (2003). Learning objects on the semantic web. Proceedings of ICALT (pp. 195199). Athens, Greece.

Mustaro, P .N., \& Silveira, I. F. (2006) Learning objects: Adaptive retrieval through learning styles. Interdisciplinary Journal of Knowledge and Learning Objects, 2, 35-46. Retrieved December 21, 2007 from http://ijklo.org/Volume2/v2p035-046Mustaro.pdf

Nkambou, R., Gouardères, G., \& Woolf, B. P. (2005). Toward learning grid infrastructures: An overview of research on grid learning services. Applied Artificial Intelligence, 19(9/10), 811-824. 
Or-Bach, R. (2004). Learning objects and metadata - From instructional design to a cognitive tool. In P. Kommers \& G. Richards (Eds.), Proceedings of AACE-World Conference on Educational Multimedia, Hypermedia and Telecommunications (pp. 2260-2263); Chesapeake, VA.

Qin, J., \& Finnerman, C. (2002). Ontological representation of learning objects. Proceedings of the Workshop on Document Search Interface Design and Intelligent Access in Large-Scale Collections, JCDL' 02, July, Portland, OR. Retrieved 7 May, 2007 from http://xtasy.slis.indiana.edu/jcdlui/uiws.html

Qin, J., \& Godby, J. (2003). Incorporating educational vocabulary in learning object metadata schemes. Proceedings of Research and Advanced Technology for Digital Libraries 7th European Conference, ECDL 2003, Trondheim, Norway, (pp. 52-57).

Quinn, C. \& Hobbs, S. (2000). Learning objects and instructional components. Educational Technology and. Society, 3(2). Retrieved January 4, 2005 from http://ifets.ieee.org/periodical/vol_2_2000/discuss_summary_0200.html

Pena, C. I., Marzo, J. L., \& de la Rosa, J. L. (2005). Intelligent agents to improve adaptability in a webbased learning environment. In C. Ghaoui, M. Jain, V. Bannore, \& L. C. Jain (Eds.), Knowledge-based virtual education; Studies in fuzziness and soft computing, (Vol. 178, pp. 141-170). Springer Berlin: Heidelberg.

Polsani, P. R. (2003). Use and abuse of reusable learning objects. Journal of Digital Information, 3(4). Retrieved April 14, 2006 from http://jodi.ecs.soton.ac.uk/Articles/v03/i04/Polsani

Retalis, S., \& Papasalouros, A. (2004). Yet another approach to support the design process of educational adaptive hypermedia applications. Proceedings to the Third International Conference on Adaptive Hypermedia and Adaptive Web-Based Systems, University of Technology, Eindhoven, (pp. 19-28).

Robson, R. (1999). Object-oriented Instructional Design and Web-based Authoring. Retrieved May 14, 2006 from http://robby.orst.edu/papers/objectoriented.html

Sampson, D., Karagiannidis C., \& Kinshuk. (2002). Personalized learning: Educational, technological and standardization perspective. Interactive Educational Multimedia, 4, 24-39.

Santos, O. C., Boticario, J. G., \& Barrera, C. (2004). A machine learning multi-agent architecture to provide adaptation in a standard-based learning management system (WSEAS). Transactions on Information Science and Applications, 1(1), 468-473.

Scalable Architecture for Interactive Learning [SAIL]. (2006). Retrieved June 22, 2006, from http://www.telscenter.org/confluence/display/SAIL/Home

Selker, T. (1994). Coach: A teaching agent that learns. Communications of ACM, 37(7), 92-99.

Silveira, A. R., Gomes, R. E., Pinto, H. V., \& Vicari, R. M. (2004). Intelligent learning objects: An agent based approach of learning objects. Proceeding of Seventh International Conference in Intelligent Tutoring Systems, Maceio, Algoas, Brazil, (pp. 886-888).

Slotta, J. D., \& Aleahmad, T. (2007). Challenges to technology enhanced learning-The case for open source and content communities. Retrieved December 22, 2007 from http://www.telscenter.org/confluence/download/attachments/7/SlottaAleahmadv5.pdf

Solomos, K., \& Avouris, N. (1999). Learning from multiple collaborating intelligent tutors: An agent-based approach. Journal of Interactive Learning Research, 10(3/4), 243-262.

Stojanovic, L., Staab, S., \& Studer, R. (2001). eLearning based on the semantic web. Proceedings of the World Conference on $W W W$ and the Internet (WebNet), Orlando, Florida, (pp. 325-334).

Sun, S., Joy, M., \& Griffiths, N. (2005a). An innovative style of learning objects and learning style pedagogic systems. Proceedings from the $6^{\text {th }}$ Annual Conference for the Higher Education Academy Subject Network for Information and Computer Science (pp. 115-119).

Sun, S., Joy, M., \& Griffiths, N. (2005b). To support adaptivity in agent-based learning systems - The use of learning objects and learning styles. Proceedings of the 5th IEEE International Conference on Advanced Learning Technologies (ICALT 2005), Kaohsiung, Taiwan, (pp. 846-847), IEEE Press. 
van Rosmalen, P., Brouns, F., Tattersall, C., Vogten, H., Bruggen, J., Sloep, P. et al. (2005). Towards an open framework for adaptive, agent-supported e-learning. International Journal in Continuing Engineering Education and Lifelong Learning, 15(3-6), 261-275.

Varlamis, I., \& Apostolakis, I. (2006). The present and future of standards for e-Learning technologies. Interdisciplinary Journal of Knowledge and Learning Objects, 2, 59-76. Retrieved December 22, 2007 from http://ijklo.org/Volume2/v2p059-076Varlamis.pdf

Vassileva, J., Greer, J., McCalla, G., Deters, R., Zapata, D., Mudgal, C., et al. (1999). A multi-agent approach to the design of peer-help environments. In: S. Lajoie \& M. Vivet (Eds.), Artificial intelligence and education (pp. 38-45). IOS Press: Amsterdam.

Whatley, J., Staniford, G., Beer, M., \& Scown, P. (1999). Intelligent agents to support students working in group online. Journal of Interactive Learning Research, 10(3/4), 361-373.

Wiley, D. (2003). Learning objects: Difficulties and opportunities. Retrieved May 7, 2007 from http://opencontent.org//docs/lo_do.pdf

Winn, W. (2002). Current trends in educational technology research: The study of learning environments. Educational Psychology Review, 14(3), 331-351.

Wooldridge, M., \& Jennings, N. (1995). Intelligent agents: Theory and practice. Knowledge Engineering Review, 10(2), 115-152.

World Wide Web Consortium (W3C). (2005). Synchronized Multimedia Integration Language (SMIL 2.1); W3C Final Recommendation 13 December 2005. Retrieved May 14, 2006 from WWW Web site: http://www.w3.org/TR/SMIL

\section{Biography}

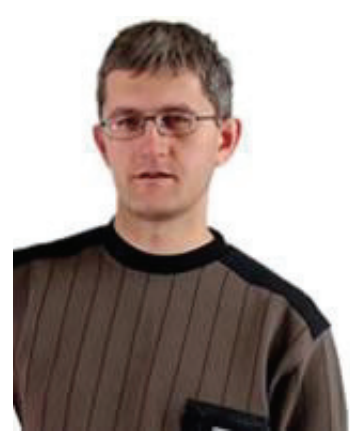

Dorian Stoilescu is a doctoral student at the Ontario Institute for Studies in Education from the University of Toronto. His research interests include learning objects, intelligent agents, knowledge building, sociocultural aspects in technology, using educational technology in mathematics and science, and computer science education. $\mathrm{He}$ is a frequent presenter at conferences in North-America and Europe. He has published also three textbooks about computer programming. 